\title{
A perífrase verbal trabalhar + de + infinitivo na língua portuguesa: de finais do século XIII a meados do século XVII
}

\author{
Verbal periphrasis trabalhar + de + infinitive in \\ the Portuguese language: from the end of the $13^{\text {th }}$ \\ century to the middle of the $17^{\text {th }}$ century
}

\author{
José Barbosa Machado *
}

\begin{abstract}
RESUMO
Pretendemos com este estudo identificar as ocorrências da perífrase trabalhar + $d e+$ infinitivo em obras que vão do português antigo (finais do século XIII) até ao português clássico (meados do século XVII), constatando a sua permanência no tempo e analisando o seu comportamento sintático e o seu valor semântico. Desenvolveremos os seguintes itens no nosso estudo: a presença da perífrase verbal no corpus selecionado; os tempos e modos do verbo semiauxiliar; os verbos principais presentes no segundo termo da perífrase; os pronomes pessoais clíticos dependentes quer do verbo semiauxiliar, quer dos verbos principais; alguns casos particulares, como o reforço do verbo semiauxiliar com outro verbo ou expressão verbal, o uso da perífrase sem a preposição de e o testemunho da sua presença no castelhano do século XV.
\end{abstract}

Palavras-chave: perífrase; conjugação perifrástica; verbo semiauxiliar; verbo trabalhar.

Recebido em 12 de maio de 2020.

Aceito em 21 de janeiro de 2021.

DOI: http://doi.org/10.18364/rc.2022n62.483

* Universidade de Trás-os-Montes e Alto Douro, jleon@utad.pt, https://orcid.org/0000-0002-6517-8948

Confluência. Rio de Janeiro: Liceu Literário Português, n. 62, p. 213-239, jan.-jun. 2022 


\section{ABSTRACT}

With this study we intend to identify all occurrences of trabalhar $+d e+$ infinitive periphrasis in works ranging from the ancient Portuguese language (late 13th century) to the classical Portuguese language (mid 17th century), verifying its permanence in time and analyzing its syntactic behavior and semantic value. The following items will be developed in our study: the presence of verbal periphrasis in the selected corpus; the tenses and modes of the semi-auxiliary verb; the main verbs present in the second term of the periphrasis; the personal clitic pronouns dependent on both the semi-auxiliary verb and the main verbs; some particular cases, such as the reinforcement of the semi-auxiliary verb with another verb or verbal expression, the use of the periphrasis without the preposition de and the testimony of its presence in the 15 th century Castilian language.

Keywords: periphrasis; periphrastic conjugation; semi-auxiliary verb; verb trabalhar.

\section{Introdução}

A sintaxe e a semântica do verbo trabalhar no português antigo e no português médio não têm sido convenientemente estudadas, em especial as perífrases formadas por este verbo, como trabalhar + de + infinitivo, trabalhar $+e m+$ infinitivo e trabalhar + por + infinitivo. Nenhum dos estudos por nós consultados acerca das perífrases verbais em português as refere (VÁZQUEZ CUESTA 1989; SQUARTINI 1998; BARROSO 2000; ALZAMORA 2018; etc.). Partiremos, tanto quanto sabemos, do zero.

Será objeto deste estudo a primeira perífrase referida, ou seja, trabalhar $+d e+$ infinitivo, que tem como significado esforçar-se por, empenhar-se em, tratar de.

Esta perífrase não é exclusiva da língua portuguesa. Existe no castelhano, como o comprovam, por exemplo, o texto nessa língua do Sacramental, redigido em 1423 por Clemente Sánchez de Vercial, cónego da catedral de León, e os Euangelios e Epistolas con sus Exposiciones en Romãce, traduzidos do latim por Gonzalo García de Santa María em 1484, ambas as obras publicadas em português em finais do século XV. 
O corpus que nos serviu de base a este estudo baseia-se em três fontes digitais: o programa Phrasis (uma base de dados de concordâncias de textos antigos); as obras digitalizadas e publicadas pelas Edições Vercial (sobretudo os primeiros livros impressos em língua portuguesa); e o Corpus Informatizado do Português Medieval (CIPM) do Centro de Linguística da Universidade Nova de Lisboa. Tendo algumas das obras sido editadas com critérios que não respeitam os documentos originais ou as cópias mais antigas conhecidas (é o caso, por exemplo, de algumas das crónicas de Gomes Eanes de Zurara), notar-se-á nos exemplos por nós apresentados neste estudo alguma disparidade de grafias. Na falta de edições mais rigorosas, utilizámos as que de momento estavam informaticamente disponíveis.

Analisaremos a perífrase de acordo com os seguintes temas: a sua presença no corpus selecionado; os tempos e modos do verbo semiauxiliar; os verbos principais presentes no segundo termo da perífrase; os pronomes pessoais clíticos dependentes quer do verbo semiauxiliar, quer dos verbos principais; alguns casos particulares, como o reforço do verbo semiauxiliar com outro verbo ou expressão verbal, o uso anómalo da perífrase sem a preposição de e o testemunho da sua presença no castelhano do século XV.

\section{A presença da perífrase no corpus}

O corpus selecionado vai de finais do século XIII, com a Vida de Santos, até à Corte na Aldeia de Francisco Rodrigues Lobo, obra publicada em 1619. Tendo feito uma busca minuciosa em textos anteriores, a Vida de Santos, baseada num manuscrito alcobacense, foi a primeira obra em que identificámos a perífrase verbal. Não significa, porém, que ela não possa ocorrer noutros textos antigos. É de crer que possa aparecer em coleções de forais e documentos notariais. O importante, porém, foi termos conseguido perceber que a perífrase já era utilizada em finais do século XIII.

A última obra do corpus é a Corte na Aldeia de Francisco Rodrigues Lobo. A partir da data em que foi publicada (1619), até 1651, ano em que foi 
impressa a Carta de Guia de Casados de D. Francisco Manuel de Melo, que não a contém, não encontrámos vestígios da perífrase em qualquer outra obra consultada.

As obras de finais do século XV e início do século XVI, excetuando a Vita Christi (1495), contêm já poucos vestígios da perífrase, o que significa que esta estava nessa época a cair em desuso. As Constituições de D. Diogo de Sousa (1497), o Roteiro da Primeira Viagem de Vasco da Gama à Índia de Álvaro Velho (início do séc. XVI) e as compilações das obras de Gil Vicente (1562 e 1586), por exemplo, não contêm qualquer ocorrência. A presença significativa da perífrase na Vita Christi deve-se ao facto, sem dúvida, de a obra ter sido traduzida no tempo do rei D. Duarte (NASCIMENTO 1999: 578; 2001: 141), altura em que a perífrase apresenta um maior número de ocorrências, como se pode verificar quer pelas obras do próprio rei, quer pelas crónicas de Fernão Lopes.

Diríamos que a perífrase trabalhar $+d e+$ infinitivo teve o seu período de utilização mais intenso entre a Crónica Geral de Espanha de 1344 e 1468, o ano em que Gomes Eanes de Zurara terminou a Crónica do Conde D. Duarte de Meneses. A partir desta data, o número de ocorrências começa a diminuir significativamente até desaparecer em meados do século XVII.

Na segunda metade do século XVI, Damião de Góis ainda a utiliza sete vezes na sua extensíssima Crónica do Felicíssimo Rei D. Manuel, e Luís de Camões utiliza-a uma vez em Os Lusíadas e outra na "Cantiga velha" das Rimas.

No século XVII, tirando a Corte na Aldeia de Francisco Rodrigues Lobo, em que ocorre uma vez, não aparece em obras tão importantes como o Discurso da Vida de El-Rei D. Sebastião de D. João de Castro (1602), o Casamento Perfeito de Diogo de Paiva de Andrade (1630) ou a Carta de Guia de Casados de D. Francisco Manuel de Melo (1651), já referida. Também não identificámos nenhuma ocorrência nas coleções de sermões do Padre António Vieira.

De todas as obras consultadas, encontrámos a perífrase verbal em 35 , que passamos a elencar, da mais antiga para a mais recente. Utilizaremos a 
sigla que vem entre parênteses para designar as diferentes obras nas citações que fizermos ao longo deste estudo.

Vidas de Santos de um manuscrito alcobacense (VS) - finais do séc. XIII: 3 ocorr.

Crónica Geral de Espanha de 1344 (CGE) - 1344: 82 ocorr.

Livro das Confissões de Martín Pérez (LC) - 1399: 3 ocorr.

A Demanda do Santo Graal (DSG) - séc. XV: 20 ocorr.

Crónica dos Sete Primeiros Reis de Portugal (CSP) - c. 1419: 36 ocorr.

Crónica de D. Pedro I de Fernão Lopes (FLP) - séc. XV: 4 ocorr.

Crónica de D. Fernando de Fernão Lopes (FLF) - séc. XV: 40 ocorr.

Crónica de D. João I (Parte I) de Fernão Lopes (FLJ1) - séc. XV: 34 ocorr.

Crónica de D. João I (Parte II) de Fernão Lopes (FLJ2) - séc. XV: 40 ocorr.

Vida de S. Teotónio (VST) - séc. XV: 2 ocorr.

Livro da Ensinança de Bem Cavalgar Toda Sela de D. Duarte (DLE) - c. 1438: 5 ocorr.

Leal Conselheiro de D. Duarte (DLC) - c. 1438: 26 ocorr.

Crónica da Tomada de Ceuta de Gomes Eanes de Zurara (ZCC) - 1450: 23 ocorr.

Crónica do Descobrimento e Conquista de Guiné de Gomes Eanes de Zurara (ZCG) - 1453: 25 ocorr.

Crónica do Conde D. Pedro de Meneses de Gomes Eanes de Zurara (ZCP) - 1463: 19 ocorr.

Crónica do Conde D. Duarte de Meneses de Gomes Eanes de Zurara (ZCD) - 1468: 14 ocorr.

Livro das Histórias da Bíblia (LHB) - séc. XV: 12 ocorr.

Horto do Esposo (HE) - séc. XV: 30 ocorr.

Castelo Perigoso (CP) - séc. XV: 9 ocorr.

Sacramental de Clemente Sánchez de Vercial (S) - 1488: 6 ocorr.

Tratado de Confissom (TC) - 1489: 2 ocorr.

Confluência. Rio de Janeiro: Liceu Literário Português, n. 62, p. 213-239, jan.-jun. 2022 
Vita Christi de Ludolfo de Saxónia (VC, I); (VC, II); (VC, III) - 1495: 95 ocorr.

História do mui Nobre Vespasiano (V) - 1496: 1 ocorr.

Evangelhos e Epistolas (EE) - 1497: 9 ocorr.

Livro de Marco Polo (LMP) - 1502: 3 ocorr.

Crónica de El-Rei D. Afonso Henriques de Duarte Galvão (CAH) - c. 1500-1550: 3 ocorr.

Crónica do Condestabre de Portugal (CCP) - 1526: 9 ocorr.

Tratado da Amizade de Duarte de Resende (TA) - 1531: 1 ocorr.

Crónica Troiana (CT) - séc. XVI: 2 ocorr.

Vida e Feitos delRei Dom João Segundo de Garcia de Resende (VFJ) 1545: 3 ocorr.

História da Antiguidade da Cidade de Évora de André de Resende (HAE) - 1553: 1 ocorr.

Crónica do Felicíssimo Rei D. Manuel de Damião de Góis (CDM) - 15661567: 7 ocorr.

Os Lusíadas de Luís de Camões (LCL) - 1572: 1 ocorr.

Rimas de Luís de Camões (LCR) - 1595: 1 ocorr.

Corte na Aldeia de Francisco Rodrigues Lobo (CA) - 1619: 1 ocorr.

O número total de ocorrências da perífrase verbal em todas estas obras é de 572. O número de formas diferentes, ou seja, não repetidas, é de 540.

Não há uma diferença significativa entre o número de ocorrências e o número de formas diferentes. Há apenas 20 formas que se repetem no corpus, ou na mesma obra, ou em várias: trabalhou de seer (CCP, 2) ${ }^{1}$; trabalhousse... de poer (CGE, 2); trabalhava... de tomar (CGE; LHB); trabalhou de tomar (CGE; TA); trabalhassem de fazer (CGE; ZCC); trabalhou de poer (CSP; FLJ2); trabalharom... de sse armar (FLF; FLJ1); trabalhou... darmar (FLF;

1 As referências às obras do corpus não contêm número de página, uma vez que a fonte é digital. Sempre que à frente da sigla que identifica a obra aparecer o número 2 ou outro número superior, significa que a forma ocorre mais do que uma vez. Se a sigla não contiver qualquer número, a forma ocorre apenas uma vez.

Confluência. Rio de Janeiro: Liceu Literário Português, n. 62, p. 213-239, jan.-jun. 2022 
FLJ2); trabalhasse de fazer (FLF; ZCG); trabalhar de tomar (FLJ2; CCP); trabalhar de fazer (S; EE); trabalhar de saber (ZCC; ZCG); trabalharem de fazer (ZCG, 2); trabalhava... de buscar (ZCP; VFJ); trabalhousse de aver (CGE, 2; FLF); trabalhousse de fazer (CGE, 3); trabalhasse daver (CGE; FLJ1; FLJ2); trabalha de fazer (CGE; DSG; HE; VC, II); trabalhouse de saber (CSP, 2; FLJ2; HE); trabalhou de fazer (CCP; CGE, 3; FLF; FLJ1; HE).

As obras com o maior número de ocorrências são a Crónica Geral de Espanha de 1344, com 82, e a Vita Christi, com 95. Estes valores elevados em relação aos das restantes obras do corpus devem-se ao facto de as duas obras referidas serem mais extensas. No entanto, a extensão do texto nem sempre explica o número de ocorrências. De facto, no Livro das Confissões de Martín Pérez, traduzido em finais do século XIV e em pleno período áureo do uso da perífrase, apenas identificámos 3 ocorrências. Ora a obra é a quarta mais extensa do corpus, depois da Crónica do Felicíssimo Rei D. Manuel de Damião de Góis. Os tradutores do Livro das Confissões, ou serviramse de outros recursos da língua para designar a ideia de esforçar-se por e empenhar-se em, ou o texto do autor, devido ao seu conteúdo, não permitiu a sua utilização.

\section{Tempos e modos do verbo semiauxiliar:}

Os tempos e modos do verbo semiauxiliar trabalhar encontram-se assim distribuídos no corpus selecionado:

\begin{tabular}{|l|l|l|l|l|}
\hline Tempos, modos e formas nominais & Ocorr. & Percent. & $\begin{array}{l}\text { Formas } \\
\text { dif. }\end{array}$ & Percent. \\
\hline Presente do indicativo & 91 & $15,91 \%$ & 88 & $16,30 \%$ \\
\hline Presente do conjuntivo & 37 & $6,47 \%$ & 37 & $6,85 \%$ \\
\hline Pretérito imperfeito do indicativo & 90 & $15,73 \%$ & 88 & $16,30 \%$ \\
\hline Pretérito imperfeito do conjuntivo & 55 & $9,62 \%$ & 51 & $9,44 \%$ \\
\hline
\end{tabular}




\begin{tabular}{|l|l|l|l|l|}
\hline Pretérito perfeito & 181 & $31,64 \%$ & 162 & $30,00 \%$ \\
\hline Pretérito mais-que-perfeito & 3 & $0,52 \%$ & 3 & $0,56 \%$ \\
\hline Futuro imperfeito & 10 & $1,75 \%$ & 10 & $1,85 \%$ \\
\hline Condicional & 19 & $3,32 \%$ & 19 & $3,52 \%$ \\
\hline Imperativo & 13 & $2,27 \%$ & 13 & $2,41 \%$ \\
\hline Infinitivo pessoal & 17 & $2,97 \%$ & 16 & $2,96 \%$ \\
\hline Infinitivo impessoal & 35 & $6,12 \%$ & 32 & $5,93 \%$ \\
\hline Gerúndio & 20 & $3,50 \%$ & 20 & $3,70 \%$ \\
\hline Particípio passado & 1 & $0,17 \%$ & 1 & $0,19 \%$ \\
\hline Totais & 572 & $100 \%$ & 540 & $100 \%$ \\
\hline
\end{tabular}

O pretérito perfeito é o tempo que tem uma presença mais significativa, seguido do presente do indicativo e do pretérito imperfeito do indicativo. Os três contabilizam mais de $63 \%$ do total das ocorrências. Os restantes tempos e modos têm uma presença bastante modesta em relação aos anteriores.

Passaremos a apresentar as perífrases distribuídas de acordo com o tempo e o modo. Nos casos em que o número de perífrases é muito extenso, daremos apenas alguns exemplos.

Presente do indicativo (88 formas diferentes): trabalha dajuntar (DLC); trabalha de ajudar (VC, I); trabalha de apanhar (VC, II); trabalha de arremedar (VC, II); trabalha de auer (HE); trabalha de cobrir (DLC); trabalha de cõprir (VC, II); trabalha de correger (VC, I); trabalha de embargar (VC; I); trabalha de fazer (CGE; DSG; HE; VC, II); trabalha de ferir (VC, III); trabalha de ir (ZCC); trabalha de o arrebatar (VC, II); trabalha de o auer (VC, I); trabalha de os derribar (VC, II); trabalhas de por (CSP); trabalhas de tomar (CT); trabalhase de andar (HE); trabalhom de teer (DLC); trabalhom de tomar (DLC); etc.

Presente do conjuntivo (37): trabalhe de buscar (CP); trabalhe de escoldrinhar (ZCG); trabalhe de fazer (VC, I); trabalhe de ho tomar (FLJ2); trabalhe de os acabar (CSP); trabalhe de se guardar (DLC); trabalhe de vingar (CGE); trabalhe... dhaver (DLC); trabalhẽ de aproueitar (VC, I); trabalhẽ 
de curar (VC, I); trabalhẽ de seer (VC, I); trabalheis de receber (CSP); trabalhem de honrrar (VC, I); trabalhem de ssaberem (DLE); trabalhemonos de empetrar (VC, III); trabalhes de acorer (CSP); trabalhes de lhe fazeres (CGE); trabalhese de as conprir (HE); trabalhesse de soltar (DLE); etc.

Pretérito imperfeito do indicativo (88): trabalhaua de auer (VC, I); trabalhaua de serem (VST); trabalhaua de sse chegar (VC, I); trabalhaua de tocarlhe (EE); trabalhaua de veer (EE); trabalhauam de o derribar (VC, II); trabalhauam de o tirar (VC, III); trabalhava de lhe fazer (CGE); trabalhava de mandar (ZCG); trabalhava de o bem rreger (FLF); trabalhava de os esforçar (FLF); trabalhava de os fazer (CSP); trabalhava de os requerer (FLJ2); trabalhava de os ver (ZCC); trabalhavase de aver (LHB); trabalhavom de buscar (FLF); trabalhavom de os embargar (FLJ1); etc.

Pretérito imperfeito do conjuntivo (51): trabalhase de ser (CSP); trabalhasem de enquererem (CSP); trabalhasem de fazer (CSP); trabalhasem de ir (CSP); trabalhasem de tirar (LHB); trabalhasem de vir (FLJ2); trabalhasse dauer (CCP); trabalhasse daver (CGE; FLJ1; FLJ2); trabalhasse de a veer (DSG); trabalhasse de o seer (VC, II); trabalhasse de passar (ZCG); trabalhasse de se defẽder (CGE); trabalhasse de sse tornar (FLJ1); trabalhasse de viinr (FLJ1); trabalhassem de fazer (CGE; ZCC); trabalhassem de hauer (CDM); etc.

Pretérito perfeito (162): trabalhamos de o fazer (CGE); trabalhamos de saber (CSP); trabalhamos de vos servyr (CGE); trabalharaõ de the levar (FLJ2); trabalharão de quebrar (FLJ2); trabalharaõ descrever (FLJ2trabalheime de entrar (VS); trabalhou de conquistar (ZCG); trabalhou de fazer (CCP; CGE, 3; FLF; FLJ1; HE); trabalhou de poer (CSP; FLJ2); trabalhou de prouer (CDM); trabalhou de saber (FLJ2); trabalhousse de embargar (CGE); trabalhousse de fazer (CGE, 3); trabalhousse de saber (HE); etc.

Pretérito mais-que-perfeito (3): trabalhara de combater (FLJ2); trabalhara de saber (DLE); trabalhara... de comprir (CGE). 
Futuro imperfeito do indicativo (10): trabalharees de a cobrar (ZCD); trabalharees... de as trazer (FLJ2); trabalharei de dar (CDM); trabalharei de perguntar (DSG); trabalharei de servir (DSG); trabalharemos de fazer (ZCC); trabalharemos de... comprir (CSP); trabalharey... de me defender (CGE); trabalharmey... de ser (VC, III); trabalharsseham de a buscar (CP).

Condicional (19): trabalharia daver (DSG); trabalharia de a aver (FLF); trabalharia de a posoyr (CSP); trabalharia de despachar (CDM); trabalharia de hir (FLF); trabalharia de lhe daar (FLJ2); trabalharia de o partir (CGE); trabalharia de partir (FLJ1); trabalharia de tomar (CGE); trabalharia... de vingar (FLF); trabalhariã de matar (CGE); trabalhariam de fazer (ZCC); trabalhariam de tomar (FLJ1); trabalharies de o poer (FLJ2); trabalharya de o desservyr (CGE); trabalharyã... de aproueitar (ZCD); etc.

Imperativo (13): trabalhaae vos de leuardes (VC, II); trabalhaaevos daproveitar (CP); trabalhade de vos defender (CGE); trabalhades de demandardes (DSG); trabalhadevos de irdes (DSG); trabalhae de os conhecer (DLC); trabalhae... de conhecerdes (DLC); trabalhai de os esconderdes (LCR); trabalhate de te esforçares (VC, III); trabalhate de te prouares (VC, III); trabalhate... de guardar (VC, I); trabalhate... de saberes (CSP); trabalhay de me aver (ZCP).

Infinitivo pessoal (16): trabalharem de... trazer (DLE); trabalharem de contentar (LCL); trabalharem de fazer (ZCG, 2); trabalhares de comprir (VC, I); trabalhares de resistir (VC, I); trabalharme de sentir (DLC); trabalharmos de as saber (DLC); trabalharmos de curar (HE); trabalharmos de guaançar ( $\mathrm{VC}, \mathrm{I})$; trabalharmos de ressurgir (CP); trabalharmos de seer (VC, III); trabalharse de o quitar (S); trabalharse de saber (DSG); trabalharsse de veer (FLF); etc.

Infinitivo impessoal (32): trabalhar daver (FLJ1); trabalhar de a saber (LC); trabalhar de ajudar (FLJ2); trabalhar de aprender (LC); trabalhar de chegar (CP); trabalhar de conhecer (DLC); trabalhar de cõprehender (VC, III); trabalhar de fazer (S; EE); trabalhar de guardar (VC, II); trabalhar de ho defemder (FLJ2); trabalhar de hyr (EE); trabalhar de lhe fazer (DSG); 
trabalhar de lho poer (FLJ2); trabalhar de o aver (CP); trabalhar de o poer (FLJ1); trabalhar de os ausentar (CA); trabalhar de poer (FLF); trabalhar de saber (ZCC; ZCG); etc.

Gerúndio (20): trabalhãdose de acabar (VC, III); trabalhamdo de fugir (FLJ1); trabalhamdo... de poer (FLJ1); trabalhamdose... de aver (ZCP); trabalhamdose... de o deffemder (FLJ2); trabalhamdosse... de o querer (FLJ1); trabalhando de defender (CGE); trabalhando de viver (DLC); trabalhando se de o buscar (ZCG); trabalhando se de vir (ZCG); trabalhandonos de conhecer (DLC); trabalhandosse de servir (CGE); trabalhandosse... daver (FLF); etc.

Particípio passado (1): trabalhada de andar e perder (ZCD).

No caso das obras de cariz religioso, o conjuntivo e o imperativo ocorrem sobretudo em contextos em que há exortações aos crentes para se esforçarem por serem bons cristãos, imitarem os santos e cumprirem os ensinamentos de Cristo e as diretrizes morais da Igreja. Nas obras de cariz histórico, como as crónicas, esses modos verbais ocorrem geralmente em contextos de exortação para tomar determinado partido ou decisão, ou esforçar-se por agradar a determinado senhor ou cumprir as suas ordens.

\section{Verbos principais no segundo termo da perífrase}

Os verbos do segundo termo da perífrase e a que chamamos principais vêm, na sua grande maioria, no infinitivo impessoal. Apresentamos na tabela seguinte aqueles que têm 10 ou mais formas diferentes:

\begin{tabular}{|l|l|l|}
\hline Verbo & Formas dif. & Ocorrências \\
\hline fazer & 44 & 58 \\
\hline haver & 30 & 34 \\
\hline pôr & 24 & 26 \\
\hline defender & 24 & 24 \\
\hline
\end{tabular}

continua 


\begin{tabular}{|l|l|l|}
\hline saber & 19 & 23 \\
\hline ser & 16 & 17 \\
\hline buscar & 16 & 17 \\
\hline tomar & 14 & 17 \\
\hline ajuntar & 11 & 11 \\
\hline ir & 11 & 11 \\
\hline tirar & 10 & 10 \\
\hline
\end{tabular}

Na posição de verbo principal, no segundo termo da perífrase, o verbo fazer é o mais frequente, seguido do verbo haver. A presença significativa destes dois verbos deve-se à significação da própria perífrase: o esforço de fazer algo ou conseguir alguma coisa.

Passamos a apresentar as perífrases de acordo com o verbo principal:

Com o verbo fazer (44): trabalha de fazer (CGE; DSG; HE; VC, II); trabalhã de fazer (VC, I); trabalha de fazer e mostrar (CSP); trabalha de se fazer (VC, III); trabalhamos de o fazer (CGE); trabalhandosse... de fazerem (FLF); trabalhar de fazer (S; EE); trabalhar de lhe fazer (DSG); trabalhar... de fazer (VC, II); trabalharam de fazer (ZCC); trabalharem de fazer (ZCG, 2); trabalharonsse... de the fazer (CGE); trabalharse... de fazer (VC, II); trabalhasem de fazer (CSP); trabalhasse de fazer (FLF; ZCG); trabalhou de se fazer (HAE); trabalhousse de fazer (CGE, 3); trabalhousse de ffazer (VS); etc.

Com o verbo haver (30): trabalha de auer (HE); trabalha de o auer (VC, I); trabalha ... de auer (HE); trabalha ... de o auer (VC, I); trabalhar daver (FLJ1); trabalhar de o aver (CP); trabalhar de os aver (CSP); trabalharia daver (DSG); trabalharia de a aver (FLF); trabalharia de aver (CGE); trabalhasse dauer (CCP); trabalhasse daver (CGE; FLJ1; FLJ2); trabalhou dauer (CCP); trabalhou de aver (CGE); trabalhou de aver treladada (LHB); trabalhousse de aver (CGE, 2; FLF); etc. Numa perífrase, o verbo haver é seguido do particípio passado de outro verbo, e neste caso é esse o principal: trabalhou de aver treladada (LHB). 
Com o verbo pôr (24): trabalhamdo... de poer (FLJ1); trabalhar de lho poer (FLJ2); trabalhar de o poer (FLJ1); trabalhar de poer (FLF); trabalhar... de poer (DLC); trabalharies de o poer (FLJ2); trabalharon de os poer (CGE); trabalhas de por (CSP); trabalhase de ho poer (CSP); trabalhase de o poer (FLJ2); trabalhasse de o poer (FLJ1); trabalhassem de o poer (FLJ2); trabalhassem de o por (ZCC); trabalhava de poer (FLF); trabalhees de poer (FLJ1); trabalhou de poer (CSP; FLJ2); trabalhou de sse poer (FLJ1); trabalhou... de o poer (FLJ1); trabalhouse de ho por (CSP); etc.

Com o verbo defender (24): trabalhade de vos defender (CGE); trabalhamdose... de o deffemder (FLJ2); trabalhando de defender (CGE); trabalhar de deffemder (FLJ1); trabalhar de ho defemder (FLJ2); trabalhar de se defemder (FLJ2); trabalharã de se defemder (ZCP); trabalharonsse de o defender (CGE); trabalharonsse... de defender (CGE); trabalhasse de defender (FLF); trabalhasse de se defẽder (CGE); trabalhava de deffender (CGE); trabalhavom de a deffender (FLF); trabalhavom... de sse defender (FLF); trabalhou de sse deffemder (FLJ1); trabalhou... de se defender (CGE); etc.

Com o verbo saber (19): trabalham de saber (VC, II); trabalhamos de saber (CSP); trabalhar de a saber (LC); trabalhar de saber (ZCC; ZCG); trabalhar de saber e entẽder (VC, III); trabalhara de saber (DLE); trabalharmos de as saber (DLC); trabalharse de saber (DSG); trabalhasse de o saber (ZCG); trabalhassẽ de saber (CGE); trabalhasse... de saber (ZCD); trabalhate... de saberes (CSP); trabalhava de saber (DLC); trabalhavam se de saber (ZCC); trabalhem de ssaberem (DLE); trabalhey de saber (ZCD); trabalhou de saber (FLJ2); trabalhouse de saber (CSP, 2; FLJ2; HE); trabalhousse de saber (HE).

Com o verbo ser (16): trabalham de ser (ZCG); trabalhar de seerẽ (HE); trabalhar de ser (FLJ2); trabalharmey... de ser (VC, III); trabalharmos de seer (VC, III); trabalhase de ser (CSP); trabalhasse de o seer (VC, II); trabalhaua de serem (VST); trabalhavam de ho ser (VFJ); trabalhavamos de seer (DLC); trabalhavasse de ser (LHB); trabalhẽ de seer (VC, I); trabalhou 
de seer (CCP, 2). Em três perífrases, o verbo ser é seguido do particípio passado de outro verbo, e neste caso é esse o principal: trabalhar de seer amado (CP); trabalhavasse... de... seerem gastadas (FLP); trabelhemos de seer coroados (VC, III).

Com o verbo buscar (16): trabalham de a buscar (DSG); trabalhando se de o buscar (ZCG); trabalharam... de buscar (ZCC); trabalharãse de buscar (V); trabalharom de buscar e achar (VC, II); trabalharsseham de a buscar (CP); trabalhaua... de buscar (ZCD); trabalhavã de buscar (ZCP); trabalhava... de buscar (ZCP; VFJ); trabalhava... de lhes buscar (CGE); trabalhavasse de buscar (CGE); trabalhavom de buscar (FLF); trabalhe de buscar (CP); trabalheime de buscar (DSG); trabalhou de buscar (FLF); trabalhou de lhe buscar (CGE).

Com o verbo tomar (14): trabalha de tomar (VC, III); trabalham de o tomar (ZCG); trabalhar de tomar (FLJ2; CCP); trabalharia de tomar (CGE); trabalhariam de tomar (FLJ1); trabalhas de tomar (CT); trabalhasse... de o tomarẽ (FLJ1); trabalhauasse de tomar (HE); trabalhava... de tomar (CGE; LHB); trabalhe de ho tomar (FLJ2); trabalhei de tomar (ZCC); trabalhey de tomar (EE); trabalhom de tomar (DLC); trabalhou de tomar (CGE; TA).

Com o verbo ajuntar (11): trabalha dajuntar (DLC); trabalharão de ajumtar (ZCP); trabalhasse dajumtar e escrever (ZCP); trabalhasse de as ajuntar (ZCG); trabalhasse de as ajuntar e escrever (ZCC); trabalhasse... de ajuntar e screuer (ZCD); trabalhasse... de se ajuntar (ZCC); trabalhom dajuntar (DLC); trabalhou dajuntar (CGE); trabalhou... dajumtar (FLJ2); trabalhou... de ajuntar (CGE).

Com o verbo ir (11): trabalha de ir (ZCC); trabalhadevos de irdes (DSG); trabalhar de hyr (EE); trabalharia de hir (FLF); trabalhasem de ir (CSP); trabalhasse de hir (FLF); trabalhassemos... de hir (VC, I); trabalhou de hyr (ZCP); trabalhou se de o ir (ZCC); trabalhousse de hyr (CGE); trabalhousse de se yr (CGE).

Com o verbo tirar (10): trabalha de thirar (CP); trabalhasem de tirar (LHB); trabalhasse de ho tirar (CDM); trabalhauam de o tirar (VC, 
III); trabalhava de tirar (LHB); trabalhavam de tirar (FLJ2); trabalhavõ de lho tirar (CGE); trabalhemos de a tirar (DLC); trabalhou de tyrar (CGE); trabalhousse de as tirar (CGE).

Os verbos comprir, servir e ver ocorrem em 9 perífrases diferentes cada um; os verbos guardar, ajudar e trazer em 7; o verbo dar em 6; os verbos acabar, andar, embargar e fugir em 5; os verbos chegar, conhecer filhar, mandar, mover, partir, seguir e vir em 4; os verbos acorrer, aproveitar, armar, bastecer, correger, derribar, levar, matar, sair, subir e vingar em 3; os verbos alçar, apanhar, apartar, arremedar, criar, curar, desviar, emendar, entrar, enviar, escoldrinhar, escrever, esforçar, estorvar, ferir, livrar, meter, passar, perguntar, preeguar, provar, receber, requerer, roubar, salvar, soltar, ter, tocar, tolher, tornar e viver em 2. Os restantes verbos, num total de 120 perífrases, ocorrem apenas uma vez cada um.

O segundo termo da perífrase pode conter dois ou mais verbos no infinitivo, ligados por uma conjunção coordenativa (e, ou): trabalha de fazer e mostrar (CSP); trabalharomsse... de fazer tirar (CGE); trabalhousse... de fazer e renovar (CGE); trabalhar de saber e entẽder (VC, III); trabalhasse de as ajuntar e escrever (ZCC); trabalhada de andar e perder (ZCD); trabalha te... de seguir e aremedar (VC, II); trabalhemonos de nos apartar e legar (VC, I); trabalhauã se ou de as neguar ou de as enffamar (VC, II); etc.

Alguns verbos principais surgem flexionados no infinitivo pessoal: trabalhaae vos de leuardes (VC, II); trabalhadevos de irdes (DSG); trabalhae... de conhecerdes (DLC); trabalhandosse... de fazerem (FLF); trabalhar de seerẽ (HE); trabalharomsse... de guardarem (FLF); trabalhate de te prouares (VC, III); trabalhate... de saberes (CSP); trabalhaua de serem (VST); trabalhavãse... de se alçarem (CGE); ; trabalhavomse do defenderem (CSP); trabalhem de ssaberem (DLE); trabalhem... de fazerem (ZCC); trabalhes de lhe fazeres (CGE); trabalhades de demandardes (DSG); trabalhai de os esconderdes (LCR); etc. 


\section{Pronomes pessoais clíticos na perífrase}

Em mais de metade das perífrases (375), o verbo trabalhar vem conjugado com os pronomes pessoais clíticos me, te, se, nos vos. O número de casos de próclise (o pronome antes do verbo) é superior ao número de casos de ênclise, o que é normal para este período da língua portuguesa.

Os pronomes pessoais dependentes do verbo semiauxiliar encontramse assim representados no corpus:

\begin{tabular}{|l|l|l|l|}
\hline Pronomes & Próclise & Ênclise & $\begin{array}{l}\text { Totais de cada } \\
\text { pron. }\end{array}$ \\
\hline me & 15 & 6 & 21 \\
\hline te & 6 & 5 & 11 \\
\hline se & 211 & 106 & 317 \\
\hline nos & 12 & 8 & 20 \\
\hline vos & 3 & 3 & 6 \\
\hline Totais gerais: & $\mathbf{2 4 7}$ & $\mathbf{1 2 8}$ & $\mathbf{3 7 5}$ \\
\hline
\end{tabular}

Em todos os casos, estamos perante a conjugação pronominal reflexa: trabalheime, trabalhate, trabalhousse, trabalhense, trabalhemos nos, trabalhaaevos, etc.

O pronome encontra-se em posição proclítica quando, regra geral, o verbo trabalhar é antecedido de preposições $(d e, e m)$, advérbios ou locuções adverbiais (a meude, ante, assi, em vão, nom, nem, nunca, sempre, soo, tanto, advérbios em -mente, etc.), conjunções ou locuções conjuncionais (ainda que, ca, como, porque, por esto, quando, que, salvo se, etc.), pronomes relativos (que, quem, qual, quantos), o pronome cada huũ e orações gerundivas.

No entanto, há casos em que a posição proclítica do pronome reflexo é aleatória: «e se trabalha com Herodes de matar o saluador.» (VC, I); «e por tanto pensam estes autiuos e se trabalhã de trazer aaquello todollos que per contemplaçom querẽ seer deuotos a deus» (VC, I); mas ygrejas nõ sem perijgo das almas se trabalhã afficadamẽte de encorporar e multipricar» 
(VC, II); «E muitos homẽes bõos se trabalharom de a guarecer se podessem.» (DSG); etc.

O pronome me em posição proclítica ocorre 15 vezes: «Outrosy nõ me trabalhey de syguir o caminho dos sãctos e de aqueles que dereytamente seruem a Deus» (TC); «Ja mais nom me trabalharei de servir Deos pois vejo que o gualardom é tal» (DSG); «en vão me trabalharei de perguntar como rei Artur morreu» (DSG); «mas que sempre me trabalhei de o servir o melhor que eu puide (FLF); «Os martires que o acompanharom forom de duas maneiras: huũs veemdo a boa emteemçom e justa querella que eu tiinha em me trabalhar de deffemder o rreino de seus tam mortaaes emmiigos (FLJ1); «porem me mandou sua Senhoria que me trabalhasse de as ajuntar e ordenar em este volume» (ZCG); etc.

O pronome me em posição enclítica ocorre 6 vezes: «E eu cuidey qui esto que era por rrazom da minha fraqueza porque era molher e trabalheime de entrar com outras molheres per muitas uezes mais todo era em uaao.» (VS); «E assi o fiz, ca eu vim ca o mais toste que pude e trabalheime de buscar as aventuras.» (DSG); «fuy favoravel ao dito conde por amor do iffante meu filho, com que ele andava, e trabalheyme de os concordar» (CSP); "trabalhei me de lhe dar fim o melhor que pude» (ZCG).

$\mathrm{O}$ pronome te em posição proclítica ocorre também 6 vezes: «Tãto ergo quer dizer que se nom mesture a entençom dalgũa malicia quãdo te trabalhares de comprir o precepto de deus.» (VC, I); «saluo se te trabalhares de resistir de todo aaquellas consolaçoões carnaaes que tees.» (VC, I); «tu que aa primeyra te esforçauas e trabalhauas de o liurar per dereyto com.» (VC, III); «e desprezando em todas as cousas, te trabalhas de pubricamente revelar contra ele» (CSP); «a sua muy Santa Igreja, remida pelo sangue de Christo, te trabalhas de por em sogeição em teus reynos» (CSP).

$\mathrm{O}$ pronome te em posição enclítica ocorre 5 vezes: «Trabalha te quanto podes de seguir e aremedar os moços paruoos:» (VC, II); «E porque tu ergo possas vençer o demo e o mũdo trabalhate cõ todas forças de guardar a virtude da humildade e da paciencia de Christo per seu exenplo.» (VC, I); 
«E tu trabalhate de te prouares se a poderas consollar ou se saberas.» (VC, III); «faze oraçõ e trabalhate de te esforçares e trabalhares que o teu spiritu sea enuolto em lenço limpo de pureza e ignoscẽcia.» (VC, III); «E trabalhate muyto de saberes se fazem justiça e derey to compridamente os que estiverem em teu luguar» (CSP).

O pronome se em posição proclítica ocorre 211 vezes: «Entom disse a suas companhas que se trabalhassen de andar pera lhes passar deante se podessẽ» (CGE); «E os clerigos que se trabalhavam de catar as seedas da Tavola Redonda» (DSG); «e nõ se trabalharian de guaanhar o perdon.» (LC); «porque nom cuidou que assi trigosamente se trabalhasse de fazer tall entrada» (FLF); «Se por comselho ou per palaura ou per obra ou per aiuda ou per outro qualquer modo se trabalhou de conronper a boa fama doutrem.» (TC); «mas agora huũ soo se trabalha de apanhar o que Christo parte.» (VC, II); etc.

O pronome se em posição enclítica ocorre 106 vezes: «E aleuãtou sobre elle os couçes trabalhandose de o abayxar aa morte.» (VC, I); «porque os saiba e trabalhasse de ssossacar e saber os desejos.» (VC, I); «quando nom podem reprehẽder dereitamẽte os dictos ou feitos dos outros trabalhamse de enfamar a emtençom com que fazem aquellas booas obras.» (VC, II); «e os escudeiros trabalharãse de buscar dõde saya tã boõ cheiro.» (V); «foron muy sanhudos poren e trabalharonsse de tolher o reyno ao padre (CGE); etc.

O pronome nos em posição proclítica ocorre 12 vezes: Em vaão pois nos trabalhamos de cõtar e de terminar os ãnos que ajnda som por vijnr aaqueste mũdo» (VC, II); «nõ penssemos ẽ estas tẽporallidades quando millitarmos e nos trabalharmos de guaançar o regno de deus.» (VC, I); «e por tal que veendo o o conhoçessemos e conhoçendoo ho amassemos e amãdo nos trabalhassemos cõ toda diligẽcia de hir aa sua gloria.» (VC, I); «ca muyto nos trabalhamos de o fazer rey.» (CGE); «Muyto cõpre a nos de nos trabalharmos de curar da nosa alma» (HE); etc.

O pronome nos em posição enclítica ocorre 8 vezes: «e nos segũdo nosso modizinho trabalhemonos quanto podermos de nos conformar a elle.» 
(VC, I); «E porẽ studemonos e trabalhemonos de nos apartar e legar com elle tã rijamẽte que nõ possamos de ligeiro desatarmos nẽ stremar delle.» (VC, I); $« \mathrm{O}$ primeiro nosso fundamento, comendarmos todos nossos feitos ao Senhor Deos, trabalhandonos de seguir sua sancta voontade» (DLC); etc.

O pronome vos em posição proclítica ocorre 3 vezes: «vos amoestamos per estes presentes escritos de todo em todo em remissão de vossos peccados que vos trabalheis de receber o nosso nobre filho» (CSP); «vos trabalharies de o poer em obra» (FLJ2); «e que vos trabalheis de haver lingua dessa gente» (ZCG).

O pronome vos em posição enclítica ocorre também 3 vezes: «Em quanto pẽssaaes de aproueitar trabalhaae vos de leuardes outros cõ vosco ẽ o caminho de deus e desejaae auer companha.» (VC, II); "Senhor, eu me parto de vos e vos filhade de manhãa vosso caminho e trabalhadevos de irdes u nos avemos todos tres a ajuntar em casa do rei Pescador». (DSG); «bem vos pareçera que todos vallem mais que vos, e assi guardarees humilldade, e trabalhaaevos daproveitar.» (CP).

Muitos dos verbos principais são também conjugados com os pronomes pessoais me, te, se, nos vos, ou vêm acompanhados dos pronomes $o$, a, os, as e the, lho, lha, lhos, lhas, todos eles, exceto em dois casos, em posição proclítica, uma vez que são antecedidos da preposição de. A distribuição é a seguinte:

\begin{tabular}{|l|l|l|}
\hline Pronomes & Próclise & Enclise \\
\hline me & 2 & - \\
\hline te & 1 & - \\
\hline se & 33 & - \\
\hline nos & 3 & - \\
\hline vos & 2 & - \\
\hline lhe(s), lha(s), lho(s) & 20 & 1 \\
\hline o, a, os, as & 93 & 1 \\
\hline Totais & $\mathbf{1 5 4}$ & $\mathbf{2}$ \\
\hline
\end{tabular}


Os pronomes $o, a$, os, as são os mais frequentes, com mais de metade das ocorrências.

O pronome me ocorre 2 vezes: «E quãdo el al quiser fazer, eu trabalharey a todo meu poder de me defender.» (CGE); «chamae Allvaro Guisado e trabalhay de me aver outro mouro, caa este no me pareçee que diz cousa que me faça proveito.» (ZCP).

O pronome te ocorre 1 vez: «Trabalha de te vingar destes outros, ca eu te ajudarey.» (CGE).

O pronome se ocorre 33 vezes: dizendolhe que per si, cõ suas gentes, se trabalhasse de se defẽder» (CGE); «trabalhavãse quanto podiam con seus amigos e conselheiros de se alçarem con o reyno e de o defender a el rey dõ Fernando.» (CGE); «E atalharõna logo e trabalharõ de se guardar dally en deante da cava o melhor que poderõ.» (CGE); "mas ante trabalhou quanto pode de se defender con aquelles que com elle tiinham» («e cadahuũ segundo milhor podia e auia ousança se trabalhaua de sse chegar mais a elle.» (VC, I); «Trabalhense de se defender aquelles que temẽ seer vençidos.» (VC, III); etc.

O pronome nos ocorre 3 vezes: «Onde Theophilo diz que quãdo o maao spiritu e os homẽs se trabalhã de nos mouer a temor ouçamos entom Christo dizẽte.» (VC, II); «E porẽ studemonos e trabalhemonos de nos apartar e legar com elle tã rijamẽte que nõ possamos de ligeiro desatarmos nẽ stremar delle.» (VC, I); «e as fõtes per que sooe de seer morta a caridade trabalha e studa de nos legar com remudados atilhos de caridade os quaaes ay que pouco curamos de consirar.» (VC, I).

O pronome vos ocorre 2 vezes: «E desque casamos cõ vossas filhas, sempre nos trabalhamos de vos servyr e ficamos sẽpre cõvosco.» (CGE); «E vos trabalhade de vos defender com dereito.» (CGE).

Os pronomes lhe, lhes, lho, lha, lhos, lhas ocorrem 20 vezes: «E os frades filharom rei Bam de Maguz e levaromno a ũa camara e trabalharomse de lhe guardar a chaga que era mui grande.» (DSG); «Certas todo o mundo se deveria a seu poder trabalhar de lhe fazer onra» (DSG); «ficaron com elle e trabalharõ de lhe fazer serviço ben e dereitamente.» 
(CGE); «e que se trabalhava quanto ella podya de lhes buscar todo mal e toda desonrra que podesse» (CGE); «trabalhei me de lhe dar fim o melhor que pude» (ZCG); etc.

Os pronomes $o, a, o s$, as ocorrem 93 vezes: «E como quer que trabalhou muito de os mudar daquela emtemção mas nunca pode.» (CT); «e nõ se quer trabalhar de a saber» (LC); «E muitos homẽes bõos se trabalharom de a guarecer se podessem.» (DSG); «E por esto se trabalhou de os sacar da çidade per arte.» (CGE); «e assy se trabalha de os derribar» (VC, II); «e aaquelle o da o demo que se trabalha de o auer com pecado.» (VC, I); «E toda a gẽte trabalhaua de ho tocar por que saya delle virtude e saaraua a todos.» (EE); «tu que aa primeyra te esforçauas e trabalhauas de o liurar per dereyto.» (VC, III); "Quando o arcebispo vyo aquele recado do papa, trabalhouse de ho por em obra» (CSP); etc.

Os dois casos se ênclise no verbo principal são anómalos: «mas agora o principe deste mundo he deitado de fora: como se mostra aos xij. cap. de Johã (trabalhaua de tocarlhe.)» (EE); «porque elles nũca se trabalharõ de crucificallo se conhoçerõ que era senhor da gloria» (VC, I).

Há 102 contextos em que a perífrase não vem acompanhada de qualquer pronome pessoal clítico, quer dependente do verbo semiauxiliar, quer dependente do verbo principal. Transcrevemos alguns exemplos: «propuse de trabalhar de fazer hũa breue copilaçom das coussas que neçesarias som aos saçerdotes que han curas de almas» (S); «O dinheiro he meu Deus e ssenpre trabalho de enganar pello auer.» (S); «e leixando por alimpar a fonte trabalhamos de alimpar os reguatos.» (VC, I); «e que nõ senta que escusado he de trabalhar de cõprehender tã grãde cousa.» (VC, III); «e dally adiãte trabalhẽ de curar:» (VC, I); «E quanto trabalhou aquel phariseu de nõ roubar algũa cousa do alheo e por nõ seer injusto.» (VC, II); «e como qual quer peccador deue trabalhar de fazer pẽdẽça ẽ a uida presente por çĩquo respeitos.» (EE); «e era ryco e trabalhaua de veer a Jhesu quẽ fosse» (EE); etc. 


\section{Casos particulares}

O verbo semiauxiliar trabalhar surge nalguns contextos reforçado com outro verbo ou com uma expressão verbal de significado contíguo.

Identificámos cinco casos com o verbo esforçar, antes ou depois do verbo trabalhar, no mesmo tempo, modo e pessoa: esforça e trabalha de cõprir (VC, II); esforçauas e trabalhauas de o liurar (VC, III); trabalha e esforça de subir (HE); trabalhaua e esforçaua de affear (VC, II); trabalhemos nos e esforçemos nos de vençermos (VC, I)

Identificámos quatro casos com o verbo estudar, antes ou depois do verbo trabalhar, também no mesmo tempo, modo e pessoa: studã e trabalhã de fazer (VC, I); studarmos e trabalharmos de seer (VC, III); trabalha e studa de nos legar (VC, I); trabalharmey e studarey de ser (VC, III).

As expressões verbais que identificámos são três, todas elas diferentes, mas semanticamente próximas: trabalha e faz prestes de o auer (VC, I); trabalha e toma grande cuydado de auer (HE); trabalhassemos e ouuessemos cuydado de fazer (VC, I).

$\mathrm{O}$ verbo semiauxiliar surge nalguns contextos reforçado pelo verbo dever. Nestes casos, o significado não é contíguo. À ideia de esforço e de trabalho é acrescentada a ideia de dever ou obrigação. $\mathrm{O}$ verbo semiauxiliar vem no infinitivo. Os contextos são os seguintes: «Empero de liçẽça e consentimẽto do que sse confesou pode descobrir, mas deue trabalhar de non usar desta lyçẽça» (S); «e nõ deue escarneçer delle nen gozarse de [sua] tribulaçon e afliçõ, ãte deue trabalharse de o quitar de tristeza e cuyta que tem (S); «e como qual quer peccador deue trabalhar de fazer pẽdẽça ẽ a uida presente por çĩquo respeitos. (EE); «E deuẽse trabalhar de seerẽ liures ẽna mẽte e ena alma (HE).

$\mathrm{O}$ verbo semiauxiliar nalguns casos surge ainda reforçado pelo verbo querer. À ideia de esforço e de trabalho é acrescentada a ideia de volição ou intenção. O verbo semiauxiliar vem também no infinitivo. Os contextos são os seguintes: «e nõ se quer trabalhar de a saber» (LC); 
«Elrey de Castela, depois que foy em idade comprida, queria trabalhar de os aver» (CSP); «e queremdosse o meestre trabalhar de o poer em obra, ouve depois comsselho de o nom fazer» (FLJ1); «ao quall fallou da maginaçõ que cuidada tiinha, e como sse queria trabalhar daver chaves feitiças pera abrir as portas de noite» (FLJ1); «e queremdose trabalhar de lho poer mamdou Lopo Guomez mover preitesia a el Rey per Guonçalo Lopez de Guoiãis» (FLJ2); "Outros se queriam trabalhar de saber o numero da frota» (ZCC); "aquelles que nõ querem trabalhar de saber $e$ entẽder» (VC, III).

Há 38 casos no corpus selecionado em que a perífrase surge de forma anómala sem a preposição de entre o verbo semiauxiliar e o verbo principal (trabalhar + infinitivo, em vez de trabalhar + de + infinitivo). Transcrevemos alguns exemplos: trabalha cheguar (VC, I); trabalha conbater (CP); trabalha correger (VC, I); trabalha fazer (VC, II; VC, III); trabalhã gaanhar (HE); trabalhã seer (VC, I); trabalha toruar (VC, I); trabalham buscar (VC, II); trabalhar trazer (DLC); trabalharam poer (ZCG); trabalharam trazer (ZCC); trabalharia remedear (VFJ); trabalharom escusarsse (CGE); trabalhase saber (CSP); trabalhasse chegar (ZCD); trabalhemos aver (CGE); trabalhemos... requerer (CP); trabalhese fazer (DLC); trabalhou reformar e enssinar (VC, II).

Nos contextos em que o verbo principal vem imediatamente depois do verbo semiauxiliar, não há explicação sintática ou fonética para a ausência da preposição. Nos restantes, talvez a interpolação de palavras e expressões entre os dois verbos possa causar o fenómeno: trabalhasse mui verdadeiramente saber (ZCG); trabalhassem com maduro consselho saber (FLF); trabalhaua muyto falar (ZCD); trabalhava, com sua prudência, me fazer (TA); trabalhe primeiro auer (VC, I); trabalhem cada dia hordenar (CP); trabalhemonos ajnda ainda em todas cousas dar (DLC); trabalhemonos ajnda ẽ todas cousas dar (VC, I); trabalhemos devotamente e cõ viveza requerer (CP); trabalho sempre viver (DLC). 
A sintaxe destas perífrases é semelhante à que que descrevemos nas perífrases com preposição, exceto no facto de o verbo principal não vir acompanhado de pronomes clíticos. Há apenas um caso que foge a este uso e que ocorre no Tratado da Amizade: «porque trabalhava, com sua prudência, me fazer mais prudente.» (TA).

Como referimos na introdução, a perífrase verbal trabalhar + de + infinitivo não era exclusiva do português. Ocorria também no castelhano. Um dos testemunhos do seu uso nessa língua é o Sacramental (1423) de Clemente Sánchez de Vercial. Esta obra foi traduzida para português e impressa em finais do século XV. No texto português, a perífrase ocorre seis vezes. Comparando as passagens correspondentes do texto castelhano com as passagens da versão portuguesa, verificamos que as desta são a tradução à letra das primeiras. $\mathrm{Na}$ tabela seguinte colocamos em confronto as passagens da edição de Sevilha de 1477 e as da edição de Chaves de 1488:

\begin{tabular}{|l|l|}
\hline Sacramental (Sevilha, 1477) & Sacramental (Chaves, 1488) \\
\hline $\begin{array}{l}\text { propuse de trabalhar de fazer hũa breue } \\
\text { copilaçom das coussas que neçesarias som } \\
\text { aos saçerdotes (Prólogo) }\end{array}$ & $\begin{array}{l}\text { propuse de trabalhar de fazer hũa breue } \\
\text { copilaçom das coussas que neçesarias som } \\
\text { aos saçerdotes (Prólogo) }\end{array}$ \\
\hline $\begin{array}{l}\text { El dinero es my dios e sienpre trabajo de } \\
\text { engañar por lo auer (Livro I, tit. xxxij) }\end{array}$ & $\begin{array}{l}\text { O dinheiro he meu Deus e ssenpre trabalho } \\
\text { de enganar pello auer (Livro I, tit. xxxij) }\end{array}$ \\
\hline $\begin{array}{l}\text { ante deue trabajarse dele tirar de tristeza e } \\
\text { cuyta que tiene (Livro I, tit. lxv) }\end{array}$ & $\begin{array}{l}\text { âte deue trabalharse de o quitar de tristeza } \\
\text { e cuyta que tem (Livro I, tit. lxv) }\end{array}$ \\
\hline $\begin{array}{l}\text { el qual se trabaja de perder e destruyr } \\
\text { aquellos (Livro II, tit. lxxij) }\end{array}$ & $\begin{array}{l}\text { o qual se trabalha de perder e destroyr } \\
\text { aaquelles (Livro II, tit. lxxij) }\end{array}$ \\
\hline $\begin{array}{l}\text { por pobreza trabaje de non poder criar los } \\
\text { fijos (Livro III, tit. xlviij) }\end{array}$ & $\begin{array}{l}\text { por pobreza trabalhey de nõ poder criar os } \\
\text { filhos (Livro III, tit. xlviij) }\end{array}$ \\
\hline $\begin{array}{l}\text { deue trabajar de nõ vsar desta licencia } \\
\text { (Livro III, tit. cxiij) }\end{array}$ & $\begin{array}{l}\text { deue trabalhar de non usar desta lyçẽça } \\
\text { (Livro III, tit. cxij) }\end{array}$ \\
\hline
\end{tabular}

Confluência. Rio de Janeiro: Liceu Literário Português, n. 62, p. 213-239, jan.-jun. 2022 
Estas são provas de que a perífrase era também um recurso linguístico do castelhano no século XV. Desconhecemos a extensão do seu uso noutras obras e a sua permanência ao longo do tempo. ${ }^{2}$

\section{Conclusão}

A perífrase verbal trabalhar $+d e+$ infinitivo é uma das muitas manifestações linguísticas ainda não suficientemente estudadas do português antigo. Sempre que a lemos nalgum texto, soa-nos a algo antiquado e desusado. No entanto, entre finais do século XIII e finais do século XV, era um dos recursos linguísticos que os portugueses tinham ao seu dispor quando pretendiam sublinhar a necessidade de se esforçarem ou empenharem a fazer ou a conseguir algo.

Embora permaneçam vestígios nalgumas obras ao longo do século XVI e início do século XVII, a perífrase foi certamente relegada como um arcaísmo, não tendo sido possível da nossa parte possível encontrar testemunhos escritos a partir de meados do século XVII que comprovem a sua permanência na língua portuguesa.

Pudemos constatar, através da análise comparativa de duas obras do corpus publicadas em português e castelhano, que a perífrase era também utilizada no castelhano, com a mesma estrutura sintática e o mesmo valor semântico que tem na língua portuguesa.

Ficaram de fora deste estudo as perífrases trabalhar $+e m+$ infinitivo e trabalhar + por + infinitivo, que merecerão tratamento à parte.

2 Encontrámos testemunhos da sua presença, por exemplo, em Las Quatro Partes Enteras de la Cronica de España de Afonso X: «por la bõdad del Imperador que se trabajaua de mejorar el estado del Imperio» (1604: 147); e no Memorial de la Vida Cristiana (1565) de Frei Luis de Granada: «para que vea el que trabaja de hacer la voluntad de Dios» (1818: 509). 


\section{Referências bibliográficas}

\section{Obras do corpus:}

Corpus Informatizado do Português Medieval (CIPM)

Phrasis, versão 2.2. Projecto Vercial, 2009.

Obras Integrais de Autores Portugueses, Edições Vercial, 2020.

\section{Outras referências:}

ALZAMORA, Helena Isabel. As Perífrases Verbais no Português Europeu Contemporâneo. Universidade Nova de Lisboa / Faculdade de Ciências Sociais e Humanas. Tese de doutoramento, 2018.

BARROSO, Henrique. Das perífrases verbais como instrumento expressivo privilegiado das categorias de natureza temporo-aspectual e simplesmente aspectual no sistema verbal do português de hoje. In: Gärtner, Eberhard, Hundt, Christine, Schönberger, Axel (Eds.). Estudos de Gramática Portuguesa (III). Frankfurt am Main: TFM, p. 91-103, 2000.

Euangelios e Epistolas con sus Exposiciones en Romãce. Salamanca. Incunábulo 31:278 existente na Biblioteca da Universidade de Upsala, Suécia, 1493.

GRANADA, Frei Luis de. Memorial de la vida cristiana. In: Obras del V.P.M. fray Luis de Granada. Madrid: Imprenta de la Publicidad, 1818.

Las quatro partes enteras de la cronica de España. Valladolid: Sebastian de Cañas, 1604.

NASCIMENTO, Aires Augusto. A tradução portuguesa da Vita Christi de Ludolfo da Saxonia: obra de príncipes em "serviço de Nosso Senhor e proveito comum”. Didaskalia, n. XXIX, p. 563-587, 1999.

A Vita Christi de Ludolfo de Saxónia, em português: percursos da tradução e seu presumível responsável. Euphrosyne, n. 29, p. 125-142, 2001. 
SQUARTINI, M.Motion periphrases in the other romancelanguages. In: Verbal Periphrases in Romance: Aspect, Actionality, and Grammaticalization. Berlin, New York: Mouton de Gruyter, p. 249-289, 1998.

VÁZQUEZ CUESTA, Pilar e Maria Albertina Mendes da Luz. Gramática da Língua Portuguesa. Lisboa: Edições 70, 1989.

VERCIAL, Clemente Sánchez de. Sacramental. Incunábulo impresso em Sevilha por Anton Martinez, Bartolomé Segura e Alfonso del Puerto. Cópia existente na Real Biblioteca del Monasterio de San Lorenzo de El Escorial, Madrid (Inc. 71-VII-27), 1477. 